\title{
Influence of Variation in Plant Characteristics Caused by Bulb Weight on Inflorescence and Individual Flower Longevity of Asiatic Hybrid Lilies after Harvest
}

\author{
José J.M. van der Meulen-Muisers and Joop C. van Oeveren \\ Centre for Plant Breeding and Reproduction Research (CPRO-DLO), P. O. Box 16, 6700 AA Wageningen, \\ The Netherlands
}

Additional index words. Lilium, selection parameter, breeding, nongenetic variation, growth chamber, keeping quality, vase life

\begin{abstract}
Nongenetic variation in cut flower longevity due to plant characteristics was investigated in whole inflorescences and individual flowers of Asiatic hybrid lilies (Lilium L.). To distinguish this variation from genetic variation, plant characteristics of five cultivars were varied by using bulbs of three significantly different weight classes per cultivar. Inflorescence longevity depended on total number of floral buds, number of buds opening and variation in bud length. Variation in individual flower longevity per cultivar appeared to be small, despite a larger number of buds per stem with increasing bulb weight. Plant characteristics caused only small nongenetic variation in individual flower longevity when compared to inflorescence longevity. Therefore, individual flower longevity appears to be the best criterion to discriminate among longevity levels for a lily breeding program.
\end{abstract}

Lily (Lilium) is one of the major bulb crops in The Netherlands, with the Asiatic hybrids as the commercially most important group for cut flower production. In December 1990, a program was initiated at CPRO-DLO to investigate the possibilities of improving flower longevity of Asiatic hybrid lilies by breeding and selection. For that purpose, it was necessary to make an inventory of the components involved and to investigate genetic variation:

Flower longevity is determined by a large number of genetic and nongenetic components (Halevy and Mayak, 1979). To improve the selection response of lily genotypes for individual genetic components of longevity, sources creating nongenetic variation must be minimized. Lily bulbs are propagated vegetatively and can, therefore, be considered genetically identical within genotypes.

Plant and flower quality in lilies may be influenced by bulb weight, which has a direct impact on plant characteristics, such as plant length, plant weight, and number of buds (Beattie and White, 1993; Miller, 1993). In breeding trials, variation in bulb weight among genotypes is expected, because for each genotype there is a minimum bulb size and weight for flowering (Rees, 1966). Therefore, bulb weight could be a possible source of undesirable variation in selection trials on longevity.

In breeding research on improvement of longevity, a parameter is needed that can be used to discriminate among longevity levels of a large group of genotypes. Because lilies produce several flowers per stem, longevity can be defined in terms of inflorescence longevity as well as in terms of individual flower longevity.

The objective of this research was to investigate the influence of variation in plant characteristics caused by bulb weight, on in florescence and individual flower longevity of Asiatic-hybrid

Received for publication 13 Mar. 1995. Accepted for publication I 1 Sept. 1995. This research was submitted by J.J.M. van der Meulen-Muisers in partial fulfillment of the requirements for a $\mathrm{PhD}$ degree. We thank J.M. van Tuyl for technical advice and discussion, G.P. Terwoert for technical assistance, L.H.W. van der Plas and F.A. Hoekstra of the Agricultural Univ. of Wageningen, A.A. De Hertogh of the State Univ. of North Carolina, and H.M.C. van Holsteijn of CPRO-DLO for critical reading of the manuscript. This work was financially supported by the Urgency Programme for Research on Diseases and Breeding of Flower Bulbs. The cost of publishing this paper was defrayed in part by the payment of page charges. Under postal regulations, this paper therefore must be hereby marked advertisement solely to indicate this fact. lilies. Based on the results the use of a definitive selection parameter for flower longevity among genotypes is proposed.

\section{Materials and Methods}

Plant materials. Bulbs of five Asiatic hybrid lily cultivars (Bright Beauty, Fashion, Harmony, Orlito, and Yellito) were obtained from commercial growers in The Netherlands and from the CPRO-DLO cultivar collection. The cultivars were chosen based on differences in plant growth and flowering characteristics, such as forcing time and number of flower buds. Three sizes of bulbs varying in circumference from about 10 to $18 \mathrm{~cm}$ were used for each genotype. Per genotype, bulbs were provided by one grower to reduce influence of bulb origin on plant characteristics (Van der Meulen-Muisers et al., 1992). The bulbs were stored at $-2 \mathrm{C}$ for about 6 months until used. Within each size class, variation in bulb weight was further reduced by selection for approximately similar weights. Three significantly different bulb weight classes per genotype were obtained (Fig. 1A).

Cultural conditions. Standard conditions were used during the preharvest, harvest and postharvest stages (Van der MeulenMuisers et al., 1992). Plants were grown in a growth chamber of the CPRO-DLO Selektron (Smeets, 1986), with a constant air temperature of $17 \mathrm{C}$, relative humidity $(\mathrm{RH}) 60 \%$, and with a $16-\mathrm{h}$ photoperiod. Photosynthetically active radiation (PAR, 400 to 700 $\mathrm{nm})$ at the top of the plants, was kept at a photosynthetic photon flux density (PPFD) of about $112 \mu \mathrm{mol} \cdot \mathrm{s}^{-1} \mathrm{~m}^{-2}$, by high-pressure metal halide lamps (HPI-T 400W, Philips). Plants were grown individually in 2.5-liter plastic pots using standard prefertilized commercial potting soil. No additional fertilization was applied. Irrigation frequency was daily.

Harvest conditions. Lily stems were harvested at anthesis of the most mature floral bud by cutting the stems at the soil level. Stems were harvested within 4 hours after onset of the photoperiod. Flower buds were counted, stems were weighed, and stem length (distance between the stem base and the petiole base of the basal flower bud), inflorescence length (distance between the petiole base of the basal and apical flower bud), and bud length were measured. Bud length was rounded off to units of $5 \mathrm{~mm}$ at the time of measuring. The leaves on the basal $15 \mathrm{~cm}$ were removed and individual stems were placed in 1-liter glass flasks containing about $500 \mathrm{ml}$ tap water. 
Postharvest conditions. Cut stems were held at a constant air temperature of $17 \mathrm{C}, 60 \% \mathrm{RH}$, and a 12-h photoperiod. PAR (400 to $700 \mathrm{~nm}$ ) at the top of the stems, was kept at a PPFD of about 14 $\mu \mathrm{mol} \cdot \mathrm{s}^{-1} \cdot \mathrm{m}^{-2}$ by fluorescent lamps(TL-D84 36W, Philips). Each individual flower was observed daily, within 4 to $6 \mathrm{~h}$ after onset of the photoperiod. Flower longevity was measured as the time between bud anthesis and deformation' of the flower, which was usually due to withering of the petals. Individual flower longevity was calculated as the mean flower longevity per stem. Longevity of the whole inflorescence was defined as the time between anthesis of the most mature floral bud of a stem and deformation of the last flower.

Completely randomized designs were used. Number of plants per treatment was 20. Data sets were analyzed as factorial analysis of variance with two-way treatment structures, using the computer package Genstat 5 (Payne et al., 1987).

\section{Results and Discussion}

Response to bulb weight. There were significant differences among bulb weight classes in plant weight (Fig. 1B), inflorescence length (Fig. 1C), and number of buds and flowers (Fig. 1D), but stem length was not influenced (Fig. 1C). The relationship between bulb weight and plant characteristics was not linear as the contribution of each unit of bulb weight to an alteration in plant characteristics decreased with increasing bulb weight. Therefore, variation within plant characteristics was relatively smaller than expected on the basis of the variation created among bulb weight classes. As for 'Yellito', the number of floral buds was constant when bulb weight increased from weight class 2 to weight class 3 (Fig. ID). Within 'Harmony', inflorescence length and number of flowers was unaffected in spite of a significant increase in number of buds and, therefore, internodes with an increase in bulb weight (Fig. $1 \mathrm{C}$ and D). Within 'Harmony', failure of floral bud opening occurred in stems obtained from bulbs of all three weight classes, which increased with increasing bulb weight (Fig. ID). Within 'Bright Beauty' and 'Orlito', stems from bulbs of weight class 3 exhibited some failure of flower opening.

Most of the varying plant characteristics we found in our study, were cited earlier by Beattie and White (1993) and Miller (1993), summarizing studies with different bulb weights in several lily species and hybrids. In our study bulb weight classes differed among cultivars, partly due to genetic differences in variation of bulb weights (Rees, 1966). Because of different production areas (growers) of the cultivars, differences in plant characteristics among genotypes can be expected (Van der Meulen-Muisers et al., 1992). Therefore, no comparisons of variation in plant characteristics among cultivars were made. Variation in plant characteristics among genetically identical plants was used to study the importance of bulb weight as a source of undesirable nongenetic variation in breeding for longevity.

Floral longevity. Inflorescence longevity increased with bulb weight in 'Bright Beauty' and 'Orlito', while for 'Fashion' this effect was found only between bulb weight class 2 and 3 (Fig. 2A). Inflorescence longevity of stems of 'Harmony' and 'Yellito' was independent of the bulb weight. Individual flower longevity was not influenced by bulb weight in all cultivars except 'Orlito', in which longevity decreased slightly with an increase of bulb weight (Fig. 2B). The ranking of the genotypes based on longevity values differed comparing inflorescence longevity and individual flower longevity. Inflorescence longevity was the longest within 'Orlito' and the shortest within 'Harmony'; whereas, individual flower longevity was the longest within 'Fashion' and the shortest within both 'Bright Beauty' and 'Harmony' (Fig. 2). Therefore, by using either inflorescence longevity or individual flower longevity as a selection criterion in breeding research on longevity, different selection results would be obtained. Differences in inflorescence longevity between plants with different bulb weights can be expected because of the effect of bulb weight on number of buds and flowers produced per stem. When the number of buds or number of flowering buds did not increase with bulb weight, as found within 'Yellito' and 'Harmony', respectively (Fig. 1D), there was no increase in inflorescence longevity (Fig. 2A). A larger number of floral buds per stem is expected to lead to an increase in the competition for the metabolizes available. Nevertheless, a reduction in individual flower longevity did not occur. So presumably all cultivars had adequate metabolizes to maintain flower longevity at a constant level.

Floral bud distribution. Within all cultivars increases in bulb weight resulted in increases in number of floral buds per bud length class (Fig. 3). 'Harmony' and 'Yellito' showed little differences in bud distribution per bud length class between bulb weight class 2 and 3 (Fig. $3 \mathrm{C}$ and E). Within 'Bright Beauty', 'Fashion' and 'Orlito', additional smaller buds were formed (Fig. 3 A, B, and D). Those three cultivars also showed a significant increase ininflores-
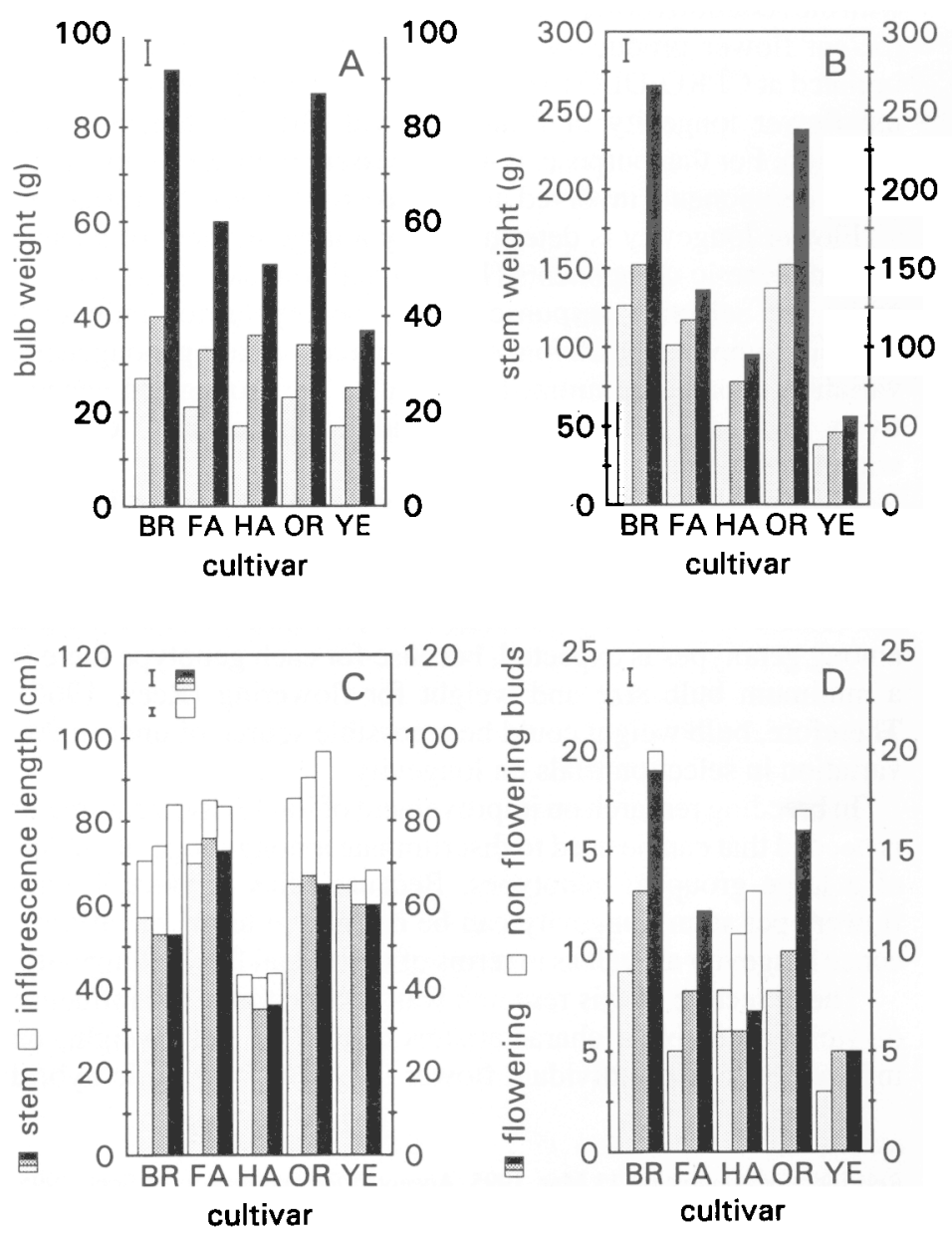

weight class 1 weight class 2 weight class 3

Fig. 1. Distribution of bulb weight per weight class (A) and effect of bulb weight on stem weight (B), stem length and inflorescence length $(\mathbf{C})$, and number of flowering and nonflowering buds (D) of the Asiatic hybrid lilies 'Bright Beauty' (BR), 'Fashion' (FA), 'Harmony' (HA), 'Orlito' (OR), and 'Yellito' (YE). Bars represent $\mathrm{LSD}$ values at $\mathrm{P}<0.05$. 

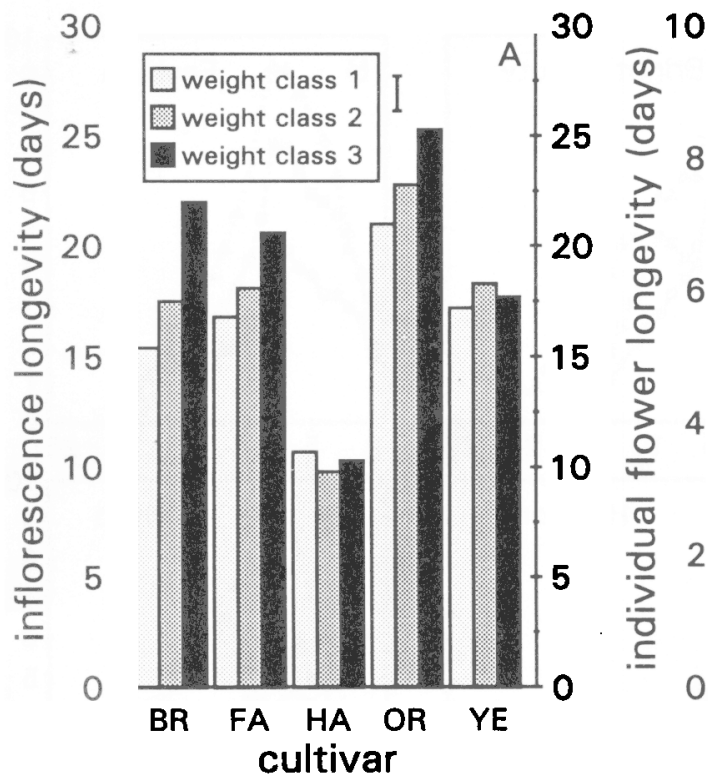

10

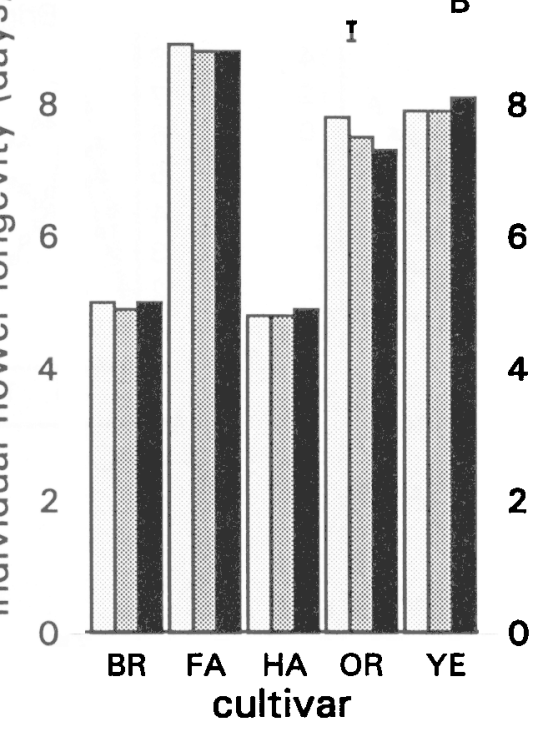

Fig. 2. Effect of bulb weight on inflorescence longevity (A) and individual flower longevity (B) of the Asiatic hybrid lilies 'Bright Beauty' (BR), 'Fashion' (FA), 'Harmony' (HA), 'Orlito' (OR), and 'Yellito' (YE). Bars represent LSD values at $P<0.05$. Bulb weight classes are defined in Fig. 1A.

'Bright Beauty' and 'Orlito'. Also differences in carbohydrate status among cultivars can be expected, that could explain the relatively low number of floral buds that reach anthesis within 'Harmony'.

Inflorescence. The influence of variation in plant characteristics on inflorescence longevity was based on the effect of bulb weight on number of buds. However, the extension of inflorescence longevity with an increase of bulb weight appeared to be smaller than expetted on basis of number of additional buds per bulb weight class (Fig. 1D, Fig. 2A). In general, an increase in number of buds per bud length class (Fig. 3) also reduced the effect of

cence longevity with bulb weight (Fig. 2A): whereas in 'Harmonv' and 'Yellito'no differences in inflorscence longevity were found among inflorescences from different bulb weight classes.

Time to anthesis. For each bud, time to anthesis decreased with an increase of bud length at the time of harvest. Per bud length, the time to anthesis was not influenced by bulb weight, except in 'Harmony' in which time to anthesis in weight class 1 was shorter than at the same bud length in the bulb weight classes 2 and 3 . Differences in time to anthesis among cultivars were due to differences in bud length at the time of anthesis. Flower buds of 'Bright Beauty' and 'Orlito' reached a length of about $90 \mathrm{~mm}$ at the time of anthesis; while flower buds of 'Fashion' reached about 85 $\mathrm{mm}$ and flower buds of 'Harmony' and 'Yellito' about $80 \mathrm{~mm}$ (Fig. 3). Within 'Harmony', differences in time to anthesis among bulb weight classes were also due to differences in bud length at the time of anthesis. In weight class 1 , anthesis occurred at a bud length of $75 \mathrm{~mm}$; whereas, in weight classes 2 and 3 anthesis took place at a bud length of $80 \mathrm{~mm}$ (Fig. 3). Time to anthesis was hardly influenced by bulb weight in spite of an increase in number of buds per length class with increasing bulb weight and, therefore, in the number of competitors for the available metabolizes.

Flower opening. Number of open flowers per day differed among plants with different bulb weights (Fig. 4), which was due to a varying number of buds per length class. There was an increase in the number of open flowers per day with an increase of bulb weight. Within 'Harmony' and 'Yellito', only small differences in number of open flowers per day were found. This was due to small differences in bud distribution among bulb weight classes (Fig. 3 $\mathrm{C}$ and $\mathrm{E}$ ). Within all cultivars, the highest number of open flowers per stem was reached one day before termination of longevity of the first flower (Fig. 2B, Fig. 4).

Floral buds of 'Harmony' failed to open from a bud length smaller than $45 \mathrm{~mm}$ at the time of harvest in bulb weight class 1 , and from a bud length smaller than $50 \mathrm{~mm}$ in bulb weight class 2 and 3. Within 'Bright Beauty' and 'Orlito', flowers did not open from a bud length at harvest smaller than 30 and $25 \mathrm{~mm}$, respectively. These stages of small buds only occurred in weight class 3 (Fig. 3). As floral bud opening often is mediated by sugar supply (Han, 1992; Spikman, 1989) failure of bud opening could be due to carbohydrate depletion, that can be expected to occur with a large increase in number of buds per inflorescence as within an increase in total number of buds. This resulted in more flowers per day instead of an increase in inflorescence longevity (Fig. 4).

Within 'Bright Beauty', 'Fashion' and 'Orlito', the time period during which open flowers were present differed among stems of different bulb weight classes; whereas, in 'Harmony' and 'Yellito' hardly any differences were found (Fig. 2A). In the three former cultivars also additional smaller buds occurred when bulb weight increased (Fig. 3). Because the time period to flowering increased with a decrease of bud length at the time of harvest, the time period after harvest during which flowers will be present will only increase with bulb weight when additional smaller buds are present.

The final effect of bulb weight on nongenetic variation in inflorescence longevity was due to the additional smaller buds, their size and, therefore, the time necessary to reach anthesis.

Small buds can vary in number within and among cultivars. This variation is due not only to variation in bulb weight but also to differences in sensitivity of genotypes to factors such as duration of bulb storage, and growing conditions (Beattie and White, 1993; Durieux et al., 1982-83; Rob, 1990a, 1990b). Although in our experiment no abortion or abscission of small buds occurred during cultivation, this might occur under less optimal preharvest conditions. Therefore, nongenetic variation in inflorescence longevity can be expected, even if bulbs of the same weight class are being used.

Individual flower. The constant longevity of individual flowers within inflorescences which was observed (Fig. 2B) has also been observed in Liatris (Han, 1992), Gladiolus (Yamane et al., 1993), and Freesia (Spikman, 1989). In Freesia individual flower longevity remained constant even when sucrose was supplied (Spikman, 1989). Liatris individual flower heads required sucrose for complete opening, after which longevity was not further influenced by the amount of sucrose supplied (Han, 1992). In both cases, an artificial sugar supply increased the number of floral buds opening and, therefore, longevity of the inflorescence. These results suggest that longevity of individual flowers of bulbous crops is maintained at a constant level within inflorescences, even after a physiological change such as an increase in internal sugar content.

From these results it is concluded that individual flower longevity is a very stable parameter in longevity evaluation. In contrast, this is not the case for inflorescence longevity. Therefore, in our breeding program for improvement of flower longevity, individual flower longevity will be used as a selection parameter. 


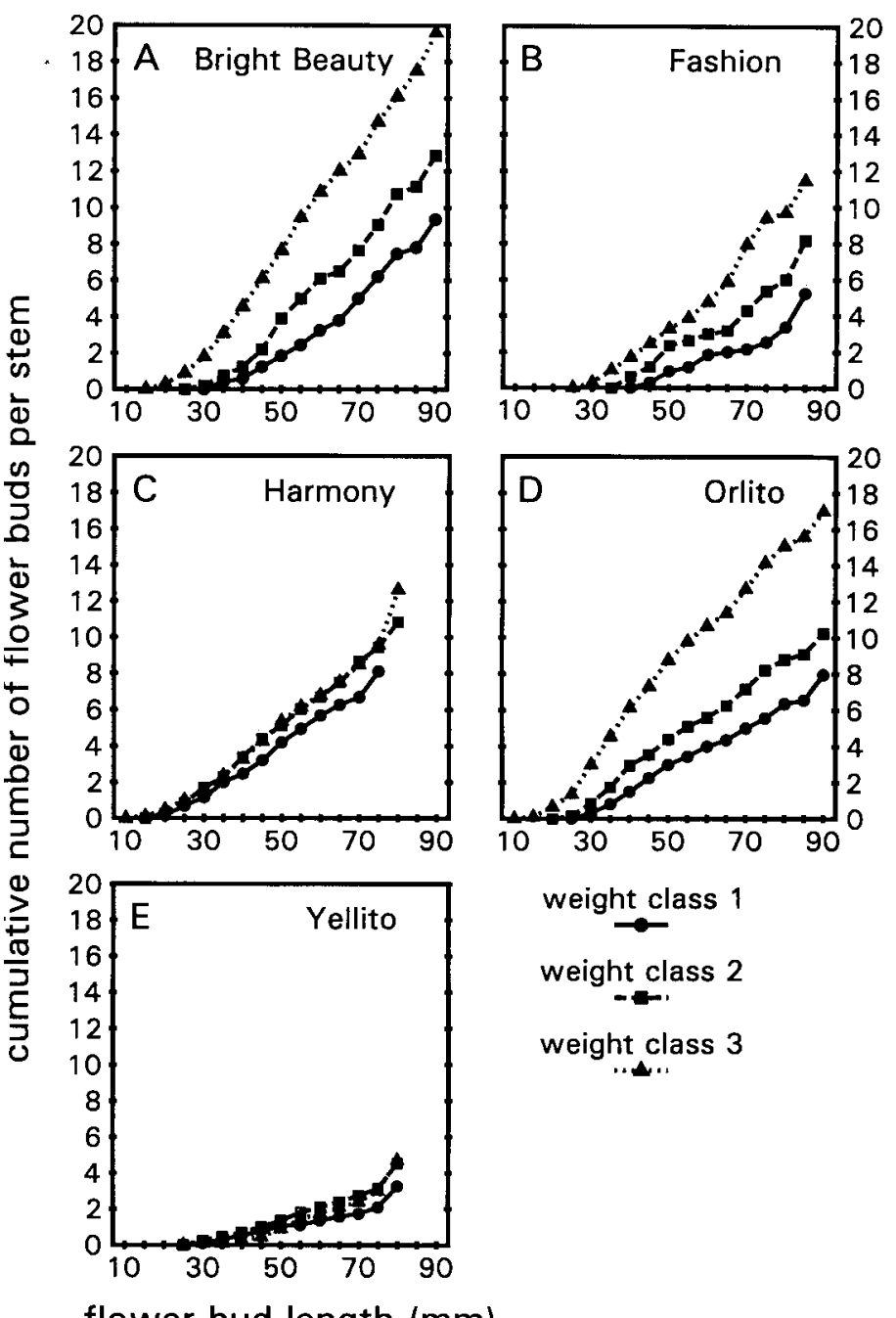

flower bud length $(\mathrm{mm})$

Fig. 3. Effect of bulb weight on the cumulative distribution of flower bud length per stem of the Asiatic hybrid lilies 'Bright Beauty' (A), 'Fashion' (B), 'Harmony' (C), 'Orlito' (D), and 'Yellito' (E). Represented are the cumulative numbers of buds until a given maximal bud length. The largest bud length class reached represents the petal length at anthesis. Bulb weight classes are defined in Fig. 1A.

\section{Literature Cited}

Beattie, D.J. and J.W. White. 1993. Lilium - Hybrids and species, p. 432454. In: A.A. De Hertogh and M. Le Nard (eds.). The physiology of flower bulbs. Elsevier, Amsterdam.

Durieux, A. J. B., G.A. Kamerbeek, and U. Van Meeteren. 1982-83. The existence of' a critical period for the abscission and a non-critical period for blasting of flower-buds of Lilium 'Enchantment'; Influence of light and ethylene. Scientia Hort. 18:287-297.

Halevy, A.H. and S. Mayak. 1979. Senescence and postharvest physiology of cut flowers. Part 1. Hort. Rev. 1:204-236.

Han, S.S, 1992. Role of sucrose in bud development and vase life of cut Liatris spicata (L.) Wind. HortScience 27:1198-1200.

Miller, W.B. 1993. Lilium longiflorum, p. 391-422. In: A.A. De Hertogh and M. Le Nard (eds.). The physiology of flower bulbs. Elsevier, Amsterdam,

Payne, R. W., P.W. Lane, A.E. Ainsley, K.E. Bucknell, P.G.N. Digby, S.A. Harding, P.K. Leech, H.R. Simpson, A.D. Todd, P.J. Verrier, R.P. White, J.C. Cower, G. Tunnicliffe Wilson, and L.J. Paterson. 1987.

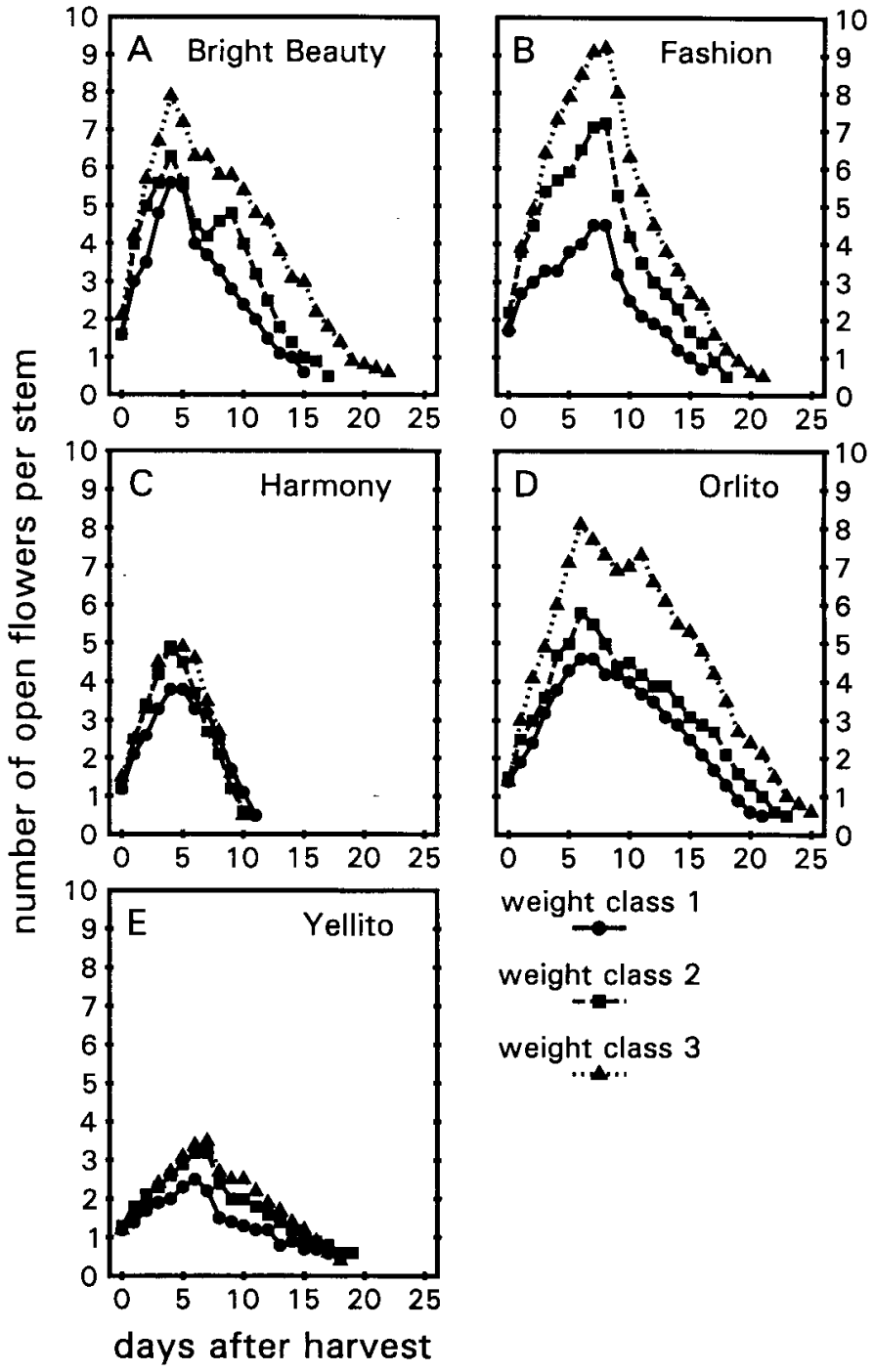

Fig. 4. Effect of bulb weight on the number of open flowers per day of the Asiatic hybrid lilies 'Bright Beauty' (A), 'Fashion' (B), 'Harmony' (C), 'Orlito' (D), and 'Yellito' (E). Bulb weight classes are defined in Fig. 1A.

Genstat 5, reference manual. Claredon Press, Oxford.

Rees, A.R. 1966. The physiology of ornamental bulbous plants. Bet. Rev. 32: $1-23$.

Rob, S.M. 1990a. Effect of high temperature on bud blast in Asiatic hybrid lily. Acta Hort. 266:141-146.

Rob, S.M. 1990b. Bud abnormalities during year-round forcing of Asiatic hybrid lilies. Acta Hort. 266:147-154.

Smeets, L. 1986. The Selektron of the Institute for Horticultural Plant Breeding (IVT), Wageningen, The Netherlands. Euphytica 35:653656.

Spikman, G. 1989. Development and ethylene production of buds and florets of cut Freesia inflorescences as influenced by silver thiosulphate, aminoethoxyvinylglycine and sucrose. Scientia Hort. 39:73-81.

Van der Meulen-Muisers, J. J. M., J.C. Van Oeveren, J.M. Van Tuyl, and H.M.C. Van Holsteijn. 1992. Examination of conditions for the selection of flower longevity in lily breeding. Acta Hort. 352:637-642.

Yamane, K., S. Abiru, N. Fujishige, R. Sakiyama, and R. Ogata. 1993. Export of soluble sugars and increase in membrane permeability of Gladiolus florets during senescence. J. Jpn. Soc. Hort. Sci. 62:575-580. 